\title{
Microencapsulation of corrosion inhibitors and active additives for anticorrosive protective polymer coatings
}

\section{V.A.Golovin* and S.A. Tyurina}

A.N. Frumkin Institute of Physical Chemistry and Electrochemistry, Russian Academy of Sciences, Leninskii pr. 31, Moscow, 119071 Russian Federation

*E-mail:golovin@rocor.ru

\begin{abstract}
One of the most promising methods to improve the protective ability of coatings is the use of microencapsulated corrosion inhibitors (MCI) and active additives in their composition. Microencapsulation technology greatly simplifies the process of compounding the polymer protective coating and allows to isolate the active components from the reactive groups of polymer resins and hardener at the stage of curing, correctly form the polymer base of the coating and avoid the negative effect of the inhibitor on the adhesion of the coating to the protected substrate. The review discusses the main methods and techniques for producing micro- and nanocapsules. The basic requirements for the quality and complex characteristics of micro- and nanocapsulated corrosion inhibitors are presented. The advantages and disadvantages of capsules using solid materials, such as powders of natural and synthetic origin, carbon nanotubes, nanotubes based on clay materials and capsules with a liquid core and a polymer shell, for example, epoxy, epoxy, silicone resins, are noted. Description of the mechanism of transfer of the contents of microcapsules in the polymer base of the coating. The possibilities of "intelligent" microcapsules releasing the inhibitor when the $\mathrm{pH}$ level changes are considered. Examples of successful scientific and technical solutions for the manufacture and implementation of micro-and nanocapsulated corrosion inhibitors in coatings with specific materials used for the manufacture of microencapsulated corrosion inhibitors are given.
\end{abstract}

Key words: corrosion protection, polymer coatings, corrosion inhibitors, microcapsules, microcapsulation methods.

Received: February 21, 2019. Published: March 12, 2019

doi: $\underline{10.17675 / 2305-6894-2019-8-2-2}$ 


\section{Introduction}

Corrosion is a serious problem in the chemical, energy, automotive, aerospace and transportation industries. According to the WCO estimate, the total direct economic damage from corrosion exceeds 1.8 trillion dollars per year [1].

Currently, polymer coatings and linings are the most common for anticorrosive protection of metal's surfaces (up to $70 \%$ of the total amount) [2,3]. One of the most promising methods for increasing the protective ability of coatings is the use of microencapsulated corrosion inhibitors (MCI) and active additives in their composition.

Microencapsulation of active additives significantly simplifies process of drawing up a compounding of a polymeric protective coating as capsule contents till a certain moment do not interact with coating material therefore its formulation can be changed easily.

Microencapsulation is a process of insulation (full or partial) of functional substance into the shell of an encapsulating material and results in formation of closed or open microcapsules. Examples of closed capsules are capsules having a liquid [4] or solid [5] core and a polymer shell; while open capsules usually consist of solid particles with welldeveloped porosity and are impregnated with an active substance

The size of the capsules varies from several nanometers to hundreds of microns and is defined by a capsulation method.

Nanoscale capsules can be obtained by the methods of aerosol spraying [6], in situ polymerization [7-9], and the sol-gel process [10].

The smallest microcapsules can be obtained by methods of electrostatic coagulation [11] (from hundreds of $\mathrm{nm}$ to $20 \mu \mathrm{m}$ ), coacervation (for more details, see Section 2) with sizes from $1 \mu \mathrm{m}$ to $1 \mathrm{~mm}$ [12-14], spray drying of the dispersion (emulsion) system [15] (up to 500 microns) or polymerization in emulsions and suspensions [16,17] (from 1 micron to several $\mathrm{mm}$ ).

Liquid, solid, or gaseous substances can be encapsulated: powders of metals and ceramics, various liquids (oils, solvents, hydrates, bases) and gases. Most of the currently produced microcapsules with active additives $[18,19]$ contain liquid filler.

However, encapsulation of solid substances has the important advantage because of increased mechanical durability. In the case of anticorrosive coatings, this greatly simplifies the process of compounds fabricating and using the most advanced method of airless spraying while application. Increased mechanical durability ensures the gradual release of the inhibitor from the microcapsule, rather than volley, as in the destruction of microcapsules containing liquid filler. Reinforced microcapsules [20] are even more resistant.

The amount of encapsulated substance is determined by the method of manufacture, the mass ratio between of shell material and encapsulated substance, the process temperature, the degree of dispersion, the viscosity of the medium, the presence of surfactants and usually is in the range $15-49 \%$ by weight [21]. 


\section{Shell of microcapsules}

\subsection{Polymers shells}

High molecular compounds and other substances of synthetic or natural origin having filmforming properties in the conditions of microencapsulation can be material of an shell.

Polysiloxane [22], poly(vinyl alcohol) [23], epoxide resins [24, 25], polyvinyl chloride [26], poly(vinyl acetate) [27], cellulose derivatives, polycarbonates, polyurethanes $[28,29]$ are the most often polymers.

The choice of shell material and the structure of microcapsules is determined, first of all, by the purpose, the required set of properties, the preferred type of release of encapsulated substances, as well as the encapsulation method. Figure 1 shows the main types of microcapsules.

microsphere

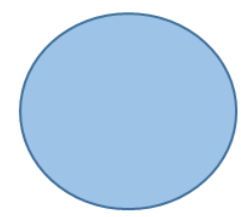

filled microsphere

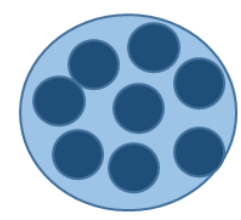

microcapsule

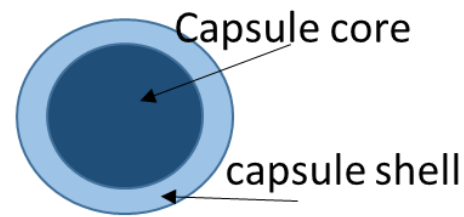

multilayer microcapsule "capsule capsule"

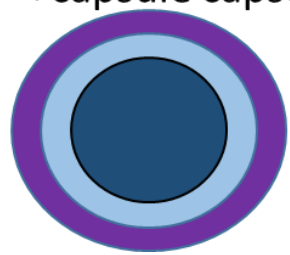

microcapsule agglomerate

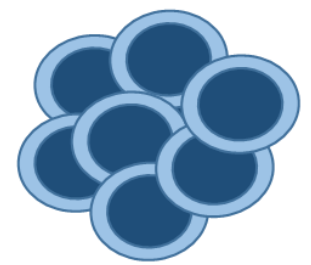

filled microcapsule

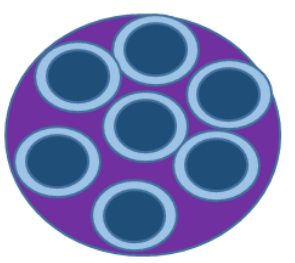

Figure 1. Main types of microcapsules.

If the material of the shells can not be applied directly to the main substance, then it is possible to use an intermediate microencapsulation in another material. As a result, a multilayer shells are formed.

It is possible to introduce incompatible substances into one common shell. To do this, each substance is located in a separate shell, and then different microcapsules are sheathed with a common shell. Moreover, there is the possibility of introducing additional necessary materials into the shell.

\subsection{Inorganic shell}

The porous structure of many natural minerals (hydrotalcites, zeolites, clay minerals) allows their use as the basis for open microcapsules. The saturation of these materials with 
active additives and corrosion inhibitors depends on the type of ion exchange (cationic, anionic) for a particular material, since this factor determines the possibility of ion exchange.

Currently, the possibility of using various artificial inorganic structures [30] including ceramic ones is being actively investigated. It allows you to control the rate of release of a corrosion inhibitor or other active substance from the capsule. Although ceramic capsules, as a rule, are open, they can be additionally closed with a polymer shell [31].

The authors of Ref. [32] describe the use of modified silicate coatings (ORMOSILS) with ceramic titanium dioxide-based nanocapsules saturated with 8-hydroxyquinoline, as well as 2-mercaprobenzothiazole, for protection of aluminum alloys. A decrease in the corrosion rate of metal by more than one order of magnitude is noted.

Inorganic nanocapsules based on cerium molybdate saturated with 3aminobenzenesulfonic acid or $1 H$-benzotriazole-4-sulfonic acid were used [33] to protect the aluminum alloy 2024-T3 (an analogue of D16, $\mathrm{Al}-\mathrm{Cu}-\mathrm{Mg}$ system). Electrochemical Impedance Spectroscopy (EIS) results showed a significant improvement in the anticorrosion properties of coatings with nanocontainers.

\subsection{Carbon nanotubes}

The possibility of using carbon nanotubes in multilayer coatings has been proven and discussed in detail in the works by Z. Iqbal [34]. It has been established that polymeric materials containing carbon nanotubes can form smart protective coatings with $p-n$ conductivity between layers. Due to this conductivity, the course of the corrosion process can be established at the electrical level. But the high cost and toxicity of nanotubes limit their widespread use in corrosion-resistant polymer coatings.

It should be noted that instead of carbon nanotubes, you can use natural nanotubes based on the clay mineral halloysite. Halloysite is a layered aluminosilicate mineral containing interlayer water $\left(\mathrm{Al}_{2} \mathrm{Si}_{2} \mathrm{O}_{3} \cdot n \mathrm{H}_{2} \mathrm{O}\right)$ [35]. Halloysite nanotubes are twisted aluminosilicate plates. They have a different composition on the inner and outer surfaces of the layer. The inner layer is positively charged $\mathrm{Al}(\mathrm{OH})_{3}$, and the outer layer is negatively charged $\mathrm{SiO}_{2}$. This feature largely distinguishes halloysite nanotubes from carbon nanotubes (having the same composition) and significantly expands the application field. There are a number of ways to increase the internal volume without changing the external diameter. This allows the use of nanotubes as capacious containers.

In addition, the unique properties of the surface of halloysite nanotubes allow selective modification of the inner space or the outer part, since some compounds form a covalent bond with aluminum oxides, when others with silicon oxides. It is also possible to use electrostatic adsorption of negatively charged components inside halloysite nanotubes, and positively charged ones on the outer surface [36-38]. 
Halloysite nanotubes filled with benzotriazole [39] are successfully used to protect copper from corrosion. In order to prevent the leakage of benzotriazole from the nanotubes, their ends are sealed by copper(II) complexation reaction.

\section{Encapsulation methods}

Encapsulation methods can be divided into two main groups:

- chemical methods involve the formation of a new phase by cross-linking highmolecular substances with polyfunctional agents or the polymerization and polycondensation on the surface of encapsulated particles. The size of the resulting microcapsules varies from a few to hundreds of microns. In the case of microencapsulation of solid particles, a polymerization initiator is usually pre-grafted onto the surface of the encapsulated substance.

When encapsulating liquid substances by polycondensation, one of the monomers dissolves in the phase of the encapsulated substance. However, the membranes thus obtained, as usual, have too high permeability for molecules with molecular weight up to 100-150 (urea, creatinine, cysteine), and the period of releasing the inhibitor and establishing equilibrium with the surrounding fluid for which is several seconds. To reduce the permeability of the membranes in the composition of the monomers introduce additional cross-linking agents [40].

- physical and chemical methods - include preservation, non-solvent precipitation, formation of a new phase with temperature, evaporation of a volatile solvent, solidification of melts in liquid media, extraction substitution, spray drying, physical adsorption [41].

A big group of methods is based on liquid-liquid phase separation, which consists in separating a phase enriched with this material from a film-forming material solution when temperature or $\mathrm{pH}$ of the solution changes, or during solvent evaporation or when a nonsolvent is added. The process of phase separation is possible to carry out in an aqueous medium, or in organic solvents [42]. This group of methods provides capsules of medium and large (up to several $\mathrm{mm}$ ) sizes.

The method of distribution drying consists of spraying a dispersion of the encapsulated substance in a solution of a film-forming material with a stream of heated carrier gas in special devices. The resulting small droplets are "hardened" by removing the solvent and curing the shells of the microcapsules.

Microencapsulation based on coacervation phenomenon is widely used to produce microcapsules containing non-polar liquid (oil) or a solid with a low-energy surface as the main encapsulated substance $[43,44]$.

The phenomenon of coacervation can often be observed in solutions of highmolecular compounds with a change in temperature, $\mathrm{pH}$, or with the introduction of lowmolecular substances. See Figure 2. 


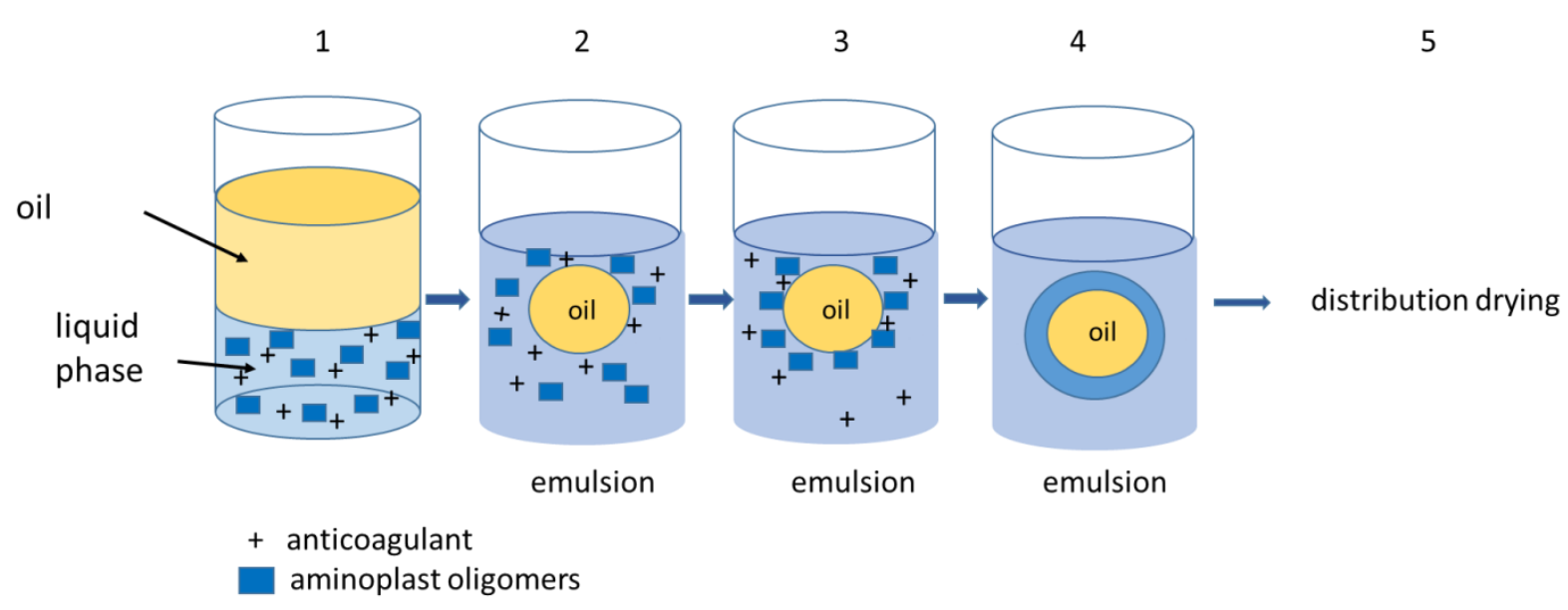

Figure 2. Schematic image of microcapsule production using coacervation phenomenon.

High molecular weight water-soluble substances are used as materials for shells in the coacervation method. These polymers can dissociate in an aqueous solution into ions and can form a liquid phase enriched with this substance. Water-soluble macromolecules of polyelectrolytes in aqueous solutions have specific electrical, conformational and hydrodynamic properties that distinguish them from ordinary non-dissociating polymers $[45,46]$.

Another possibility of microencapsulation is electrostatic microencapsulation. The encapsulated substance and the molten film-forming substance are sprayed and as a result, oppositely charged droplets are formed, which, when colliding with each other, combine to form capsules.

Solids can be encapsulated in a vacuum. For this, the shell material is evaporated in vacuum and condensed on the encapsulated material [47].

When choosing the method of encapsulation, it is necessary to be guided by the necessary set of properties of the final product, the cost of the process and the properties of the original encapsulated substances.

\section{Mass transfer from MCI}

It is considered that there are two main mechanisms for transferring the contents of a microcapsule into the coating volume:

a) phase transfer through open pores in the capsule walls or defects arising during coating;

b) molecular transfer through the wall of the capsule by the diffusion mechanism.

The principal difference between these two mechanisms is that during phase transfer, the composition of the substance carried out of the capsule does not change, whereas with molecular transfer, the composition may change due to selective diffusion. 


\subsection{Phase transfer}

The main cases of phase mass transfer is the transfer out of so-called "open capsules" or destructible closed capsules. Two most common causes of mechanical failure of closed polymer-coated microcapsules are usually considered: damage during the coating process (especially dangerous in airless spraying) and damage due to local mechanical action on the coating.

As a result of local damage or growth of internal stresses, microcrack nucleation and growth occurs in the polymer coating, which can lead to the destruction of microcapsules with active additives. One of the solutions is the use of reinforced microcapsules [20], which are an inert sorbent with a corrosion inhibitor impregnated into it and coated with a polymer shell. This allows you to eliminate the destruction at the stage of application and to ensure the gradual release of the active filler and long-term inhibitory effect.

\subsection{Diffusion transfer}

During diffusion mass transfer, the most important characteristic of polymer shells used in microencapsulation is their diffusion permeability with respect to the contents of microcapsules, to the components of the corrosive environment in which the coating will be used or stored (water, electrolyte aqueous solutions, organic solvents, atmospheric oxygen atmosphere, etc.

The highest permeability values are noted for highly elastic rubber-like polymers, the lowest for rigid polymers having a large number of polar groups. The permeability of cross-linked polymers is less than linear, but with a slight degree of cross-linking, this pattern is weakly expressed $[48,49]$.

Under real conditions, polymeric membranes (shells) are in contact with aqueous and non-aqueous (organic) solvents, both from the external environment and from the contents of the microcapsules. Polymers with polar groups in the chain are characterized by a significant increase in permeability in the wetted state, for non-polar polymers such a change is insignificant. The same dependence is observed in the diffusion of organic solvents [50].

Hydrophobic polymers adsorb electrolytes to an insignificant degree, but the permeability of such films for volatile electrolytes rather high [51].

The permeability of hydrophobic polymers for non-volatile electrolytes is approximately three orders of magnitude lower, but the addition of polar solvents to aqueous solutions dramatically increases the permeability of hydrophobic polymers [52]. Films of hydrophilic polymers also differ in selective permeability with respect to components of electrolytes. 
The rate of diffusion of the encapsulated substance into the environment during the swelling of the shells is described by a first-order equation and is inversely proportional to the thickness of the walls of the capsules.

The permeability of the shells of microcapsules depends on the environmental parameters during storage and use of microcapsules. It is established that permeability decreases with decreasing temperature and increasing pressure [53].

\subsection{Mass transfer control}

Changing the composition and properties of the internal electrolyte solution in polymer coating can be an effective trigger for controlled inhibitor release out of microcapsules.

In most cases, under-film corrosion proceeds by electrochemical type and is accompanied by local changes in $\mathrm{pH}$ [54] and electrochemical parameters. Contact or slit corrosion is also accompanied by a change in the $\mathrm{pH}$ value.

Anti-corrosion coatings containing microencapsulated inhibitors are developed in [55] with microcapsules reacting to changes in the $\mathrm{pH}$ inside the coating. Under-film corrosion process causes a change in the $\mathrm{pH}$ of the internal solution and starts the alkaline hydrolysis of capsule polymer shell, which in turn leads to the spontaneous opening of the microcapsule wall. The polymer walls of microcapsules are obtained on the basis of melanin-formaldehyde and urea-formaldehyde oligomers and contain a cross-linking agent with one or several ether or mercaptan groups.

To obtain $\mathrm{pH}$-sensitive capsules was used polymerization in situ; were encapsulated $\mathrm{pH}$ indicators with inhibitory properties: phenolphthalein, phenolsulfonphthalein, fluorescein, rhodamine B and additives with self-healing action for epoxides and siloxanes; and also various solvents. Microencapsulation of $\mathrm{pH}$ indicators with inhibitory properties is of interest for the creation of coatings that timely report the occurrence of corrosion, for the timely adoption of appropriate measures. Microcapsules containing traditional corrosion inhibitors, such as sodium molybdate $\mathrm{Na}_{2} \mathrm{MoO}_{4}$, cerium nitrate $\mathrm{Ce}\left(\mathrm{NO}_{3}\right)_{3}$, sodium phosphate $\mathrm{NaH}_{2} \mathrm{PO}_{4}$, calcium metaborate were also manufactured.

The size of the obtained microcapsules varies from $200 \mathrm{~nm}$ to 200 microns, but it is more expedient to strive to obtain microcapsules with a size of about 1-5 microns. You can control the size of the microcapsules obtained by selecting the appropriate emulsion formulation or changing the mixing conditions during the emulsion manufacturing process.

Corrosion tests of steel plates, painted with paintwork material, with various kinds of microcapsules, in the salt fog chamber according to ASTM B 117 showed their high efficiency. The polymer base of the studied compositions was epoxy, epoxyurethane, silicone resins.

The developed $\mathrm{pH}$-sensitive microcapsules ensure the release of their contents, regardless of the cause of corrosion and the type of defects such as air bubbles, uneven coating thickness, permeability, porosity or edge effect. 
The method of obtaining reinforced microcapsules, which is an inert sorbent with etidronic acid or 1-hydroxyethane 1,1-diphosphonic acid (HEDP) and aminotris(methylenephosphonic acid) (ATMP) impregnated in it, is described in [56]. Capsules are coated with a polymer shell. The adducts of these phosphonic acids [57], as well as adducts of other phosphorus-containing acids [58], are effective corrosion inhibitors.

It is recommended to use aluminum oxide, silicon oxide, zeolites of various grades as an inert sorbent. The size of the capsules is from 20 to 60 microns. Epoxy resins were used as the polymer shell. These polymeric materials are optimal for forming both the matrix of the coating $[59,60]$ and the shell of the microcapsules. Epoxy resins are cured with hardeners of both the amine type and acids, including phosphonic, and this results in coatings and shells with different diffusion characteristics.

According to the diffusion transfer of inhibitors eluted from microcapsules, the diffusion coefficients were estimated. It was shown that the shell of the formed microcapsules provided effective washing out of the acid with water from the microcapsules into the polymer coating matrix. In addition, it was found that microcapsules shell is resistant to water and organic solvents.

To assess the inhibitory effect of microcapsules electrochemical impedance spectroscopy (ISO 16773-2: 2016 (E)) studies were conducted. The results of these measurements showed a significant decrease in the corrosion rate due to the introduction of microcapsules with corrosion inhibitors [61].

One of the new significant trends in the creation of protective anti-corrosion coatings is the use of microcapsules to achieve both an inhibitory effect and a self-healing effect [62-64]. It is shown that their use allows to increase the reliability of protection against corrosion [65].

The effectiveness of the introduction of nanocapsules into the composition of protective polymeric coatings is also confirmed by the data of [66] for coatings based on dispersions of water-borne protective coatings. The developed nanocapsules consisted of a liquid core and a polymer shell. The structure was stabilized using surfactants. In the work under consideration, the following were used as surfactants: Synperonic PE / F68, Lutrol F68 and benzalkonium chloride.

Synperonic PE / F68 and Lutrol F68 are non-ionic surfactants, and benzalkonium chloride is a cationic surfactant. The nature of surfactants determines the charge on the surface of the nanocapsule. An example of such a nanocapsule is shown in Figure 3 


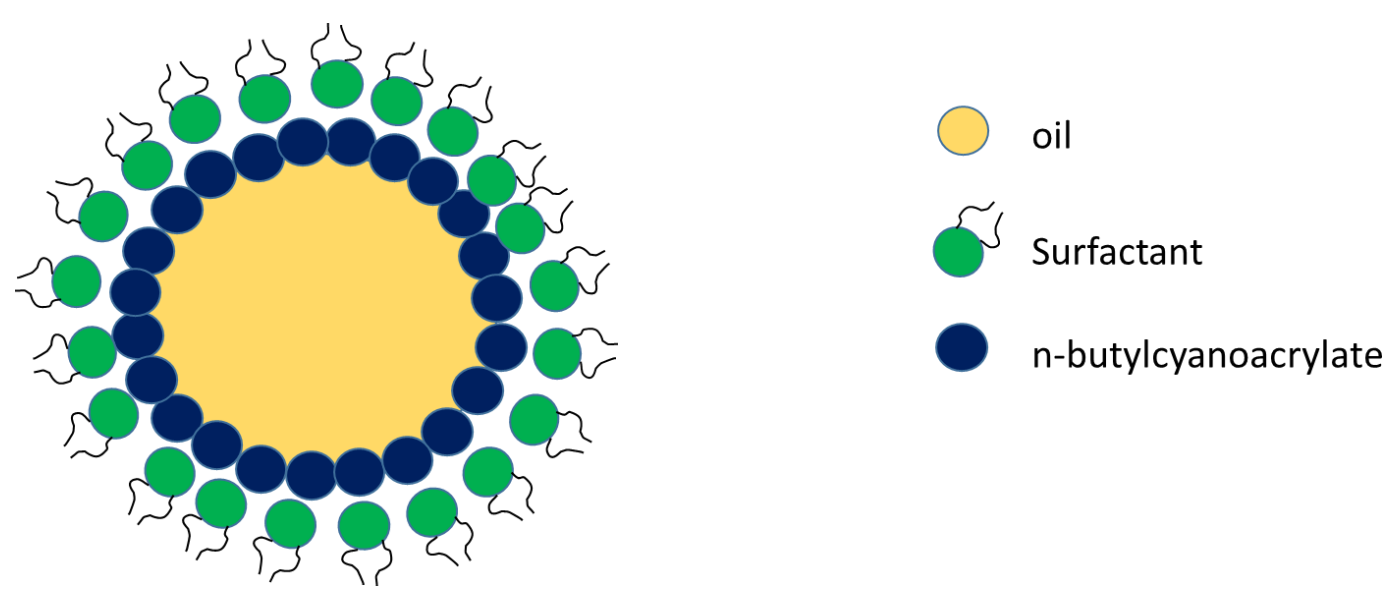

Figure 3. Schematic image of nanocapsules.

As an encapsulated material, nanocapsules may contain corrosion inhibitors and selfhealing resins, which, in the event of damage, sometimes have an insulating effect and inhibit the further development of corrosion.

The literature also contains information on obtaining multilayer nanocapsules containing chitosan $[67,68]$. At low $\mathrm{pH}$ values, protonation of amine groups contained in chitosan occurs and a cationic polyelectrolyte is formed. This effect is used in the manufacture of multi-layer capsules. At high $\mathrm{pH}$ values, deprotonation occurs and chitosan is converted from a soluble cationic polymer to an insoluble polymer [69]. The size and rigidity of the molecules depend on the $\mathrm{pH}$ level, salt concentration and mixing process. At low $\mathrm{pH}$ values $(<3.5)$, repulsive forces in molecules increase and their rigidity increases [70]. At $\mathrm{pH} 4-6$ the molecule is twisted relatively continuously, and a further increase in $\mathrm{pH}$ leads to aggregation.

Works on the microcapsulation of sodium oleoylsarcosinate are also of interest [71]. The choice of sodium oleoyl sarcosinate is explained by its high adsorption and inhibitory ability with respect to iron, copper, zinc, D16 aluminum alloy and other metals [72-74]. The structural formula of sodium oleoyl sarcosinate is shown in Figure 4 below.

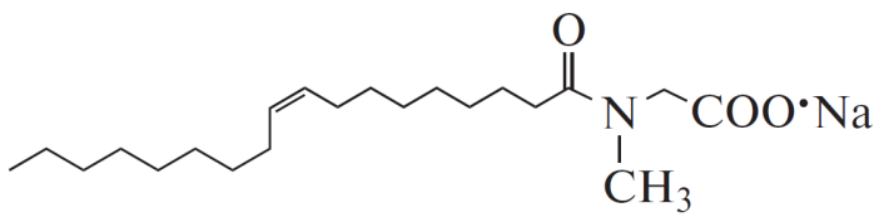

Figure 4. The structural formula of sodium oleoyl sarcosinate.

Since this inhibitor has a high solubility in water, which negatively affects the properties of polymeric coatings upon its direct introduction, the possibility of using it by preliminary placement in nanocapsule is considered. The sol-gel method was used for obtaining spherical mesoporous particles-containers on micelles of the indicated corrosion 
inhibitor. The size of the synthesized particles varies from 150 to $300 \mathrm{~nm}$. Depending on the composition of the reaction mixture, the amount of inhibitor per $1 \mathrm{~g} \mathrm{of} \mathrm{SiO}_{2}$ may be $1.1 \mathrm{~g}$.

Such capsules have $\mathrm{pH}$ sensitivity, which makes it possible to regulate the rate of release of the corrosion inhibitor from the porous carrier. These results resonate well with the above results of German scientists. The effectiveness of the introduction of these nanocapsules in the composition of the alkyd primer coating PF-0294 is shown. A significant increase in the protective ability of the polymer coating deposited on low carbon steel and D16 aluminum alloy has been established. The optimal concentration of microcapsules containing sodium oleoylsarcosinate in the coating reaches $4 \%$.

Cetyltrimethylammonium bromide and katamin $\mathrm{AB}$ were also tested in the synthesis of encapsulated corrosion inhibitors [72]. Their effectiveness in protection against hydrogen sulfide corrosion of various carbon steel grades is shown. In addition, it was found that the dissolution products of the silica matrix have an additional inhibitory effect.

\section{Application of MCI in other types of coatings}

Capsules with a corrosion inhibitor may be used not only in the composition of polymer paints, but also in the electroplating. The literature describes the successful experience of using nanocapsules, additionally coated with a layer of chitosan, in electroplating. Scientists have managed to integrate nanocapsules with a corrosion inhibitor into the galvanic layer through the implementation of sulfate-chloride nickel plating.

The presence of a chitosan layer contributes to a change in the charge of the nanocapsules [75]. If the treated surface is damaged, nanocapsules destroyed and release the encapsulated inhibitor and thereby have a protective effect. A schematic representation of this type of nanocapsules is shown in Figure 5.

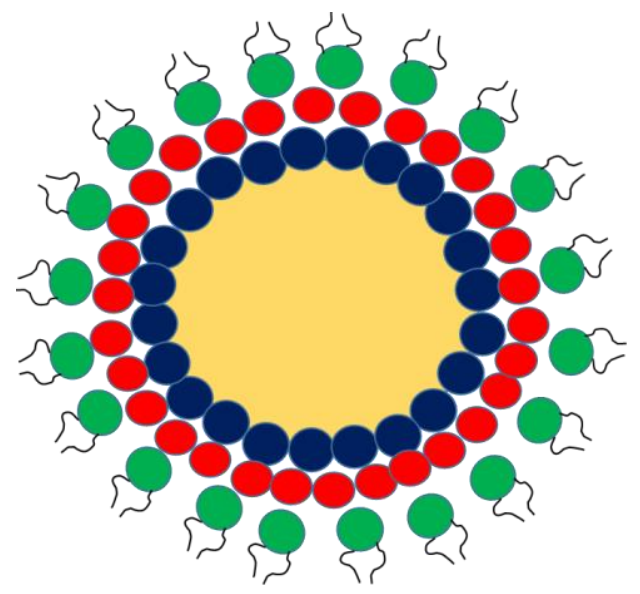

oil

Surfactant

n-butylcyanoacrylate

chitosan

Figure 5. Schematic representation of nanocapsules coated with chitosan. 
Nanocapsules intended for introduction into the electroplating layer contain as inhibitors corrosion additives such as Additive G50, Rewocoros AC 28, Revocoros AC 101, previously used to protect aluminum, iron, zinc, copper, lead, magnesium. According to [76] Additive G50 is polyoxyalkylene cellulose. It is insoluble in water, but it is well soluble in emulsifiable polar organic liquids. The acidic groups of the inhibitor serve as metallophilic bridges, and, polyoxyalkylene as a hydrophobic polymer base (Figure 6, Figure 7). The base holds the bridges and at the same time insulates the metal surface.This inhibitor is well combined with paint coatings and with other inhibitors. A feature of this substance is its long-lasting efficacy even at very low concentrations and high efficacy at $\mathrm{pH}$ values of 5-9 [77].<smiles>[R]C(C)(C)CCOC(C)(C)P</smiles>

Figure 6. General structure of polyoxyalkylene.

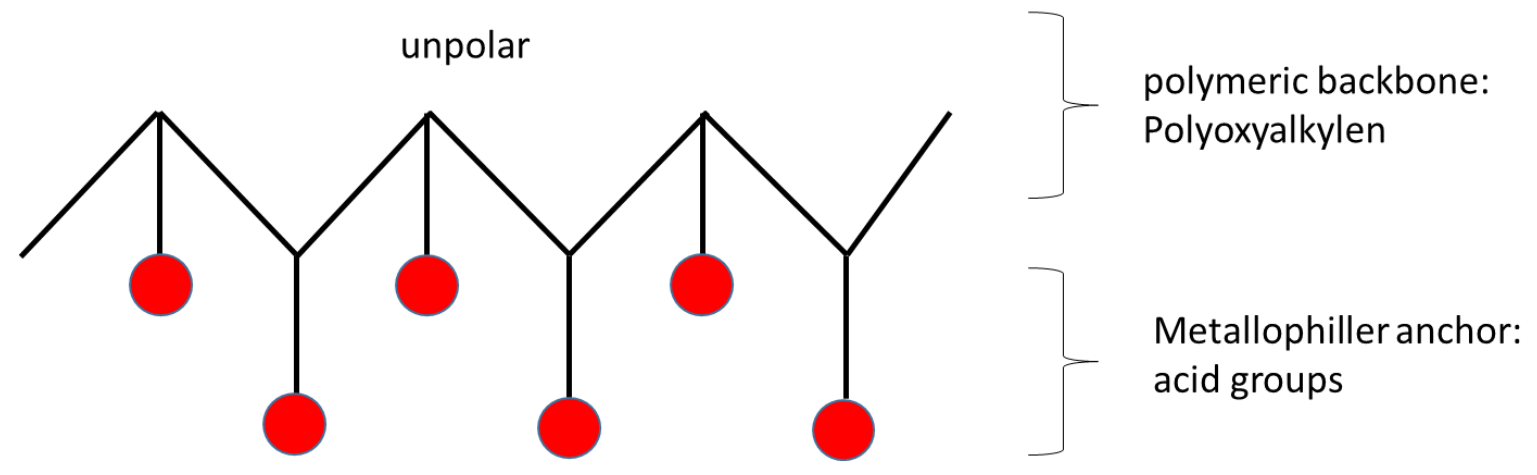

Figure 7. Schematic representation of a polyoxyalkylene based inhibitor.

Inhibitor Rewocoros $\mathrm{AC} 28$ is a viscous liquid with a $\mathrm{pH}$ of 10 , insoluble in water and capable of emulsification. It is used as a lubricating coolant. It consists of two active components, diethanolamine and $N, N$-bis(2-hydroxyethyl)oleamide [78]. Below are the structures of these components (Figure 8, Figure 9).

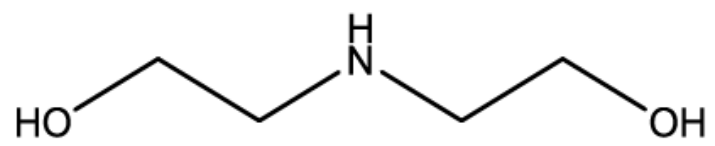

Figure 8. The structure of diethanolamine (2,2-iminodiethanol). 


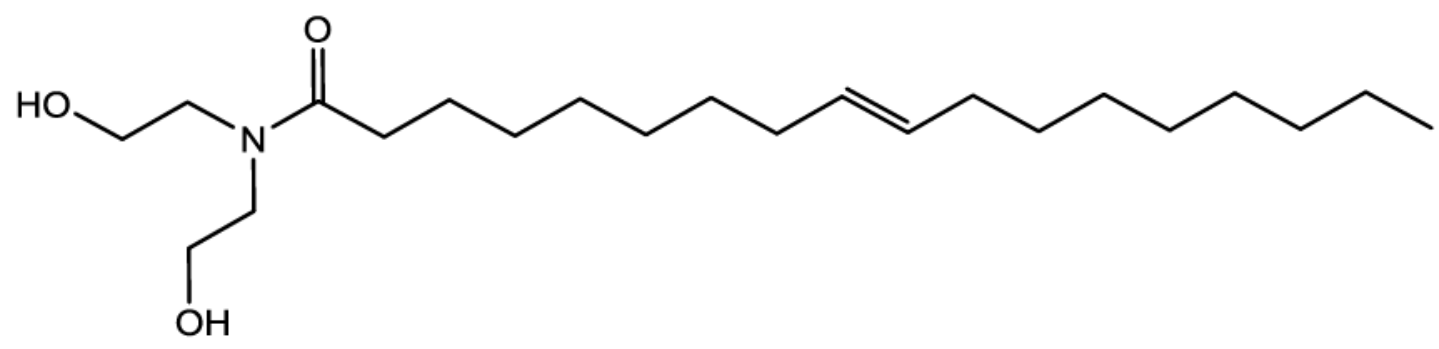

Figure 9. Structure of $N, N$-bis(2-hydroxyethyl)oleamide.

Revocoros AC 101 inhibitor consists of two active components, amidoethanolpolyethoxylate and 2-aminoethanol. It is a viscous brown liquid, insoluble in water at a temperature of $t=20^{\circ} \mathrm{C}$, but emulsifiable. This inhibitor is also used as a coolant (Figure 10, Figure 11) [79].

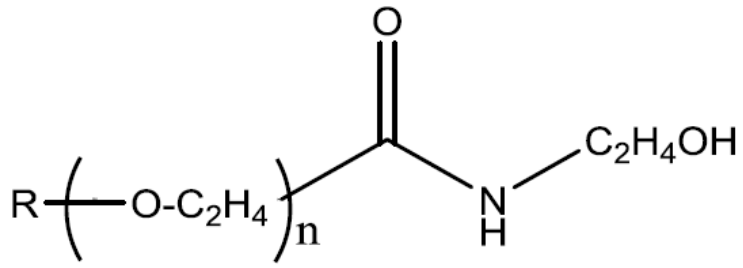

Figure 10. Structure of amidoethanol-polyethoxylate.

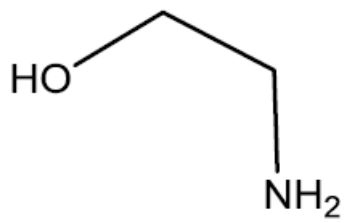

Figure 11. The structure of 2-aminoethanol.

Due to the functionalization of the surface, the environmental impact on it is reduced and the frequency of maintenance and repair costs are reduced. All this leads to an increase in the durability of the materials used and the conservation of resources [80].

\section{Conclusion}

The technology of microencapsulation of inhibitors is a promising and dynamically developing method since the beginning of the 2000s to prevent corrosion processes and reduce the speed of their development.

Microencapsulation of inhibitors allows to isolate the active components from the reactive groups of polymer resins and hardener at the stage of curing, correctly form the polymer base of the coating and avoid the negative effect of the inhibitor on the adhesion of the coating to the protected substrate. The release of the inhibitor from the microcapsule 
can occur when the coating is destroyed, initiated by the diffusive transfer of water through the coating or due to the onset of underfilm corrosion [81].

However, in order to provide a protective effect, microcapsules must contain a sufficient amount of inhibitor to have the necessary rate of release of the inhibitor. The shell of the microcapsules must have a sufficient level of mechanical properties and, in general, the microcapsules must have a reasonable shelf life [82-85].

\section{References}

1.G. Smitch, M. Schütze, G. Hays, W. Burns, En-Hou Han, A. Pourbaix and G. Jacobson, The world corrosion organization, http://www.corrosion.org/ima-ges_index/ whitepaper.pdf, May 2009, 44 pp.

2. I.V. Semenova, G.M. Florianovich and A.V. Khoroshilov, Korrosiya i zashchita ot korrosii (Corrosion and corrosion protection), Moscow, FIZMATLIT, 2010, 416 pp. (in Russian).

3. E. Kunze, Korrosion und Korrosionsschutz (Corrosion and corrosion protection), Vol. 3, Wiley-VCH, 2001, 1680 pp. (in German).

4. S.S. White, N.R. Sottos, P.H. Geubelle, J.S. Moore, M.R. Kessler, S.R. Sriram, E.N. Brown and S. Viswanathan, Autonomous healing of polymer composites, Nature, 2001, 409, 794-797.

5. N. Wang, K. Cheng, H. Wu, C. Wang, Q. Wang and F. Wang. Effect of nano-sized mesoporous silica MCM-41 and MMT on corrosion properties of epoxy coating, Progr. Org. Coat., 2012, 75, 386-391.

6. B.S. Hatami, M. Peikaria, A. Ashrafib and M. Samadzadeha, Self-Healing Ability and Adhesion Strength of Capsule Embedded Coatings Micro and Nano Sized Capsules Containing Linseed Oil, Prog. Org. Coat., 2012, 75, no. 4, 292-300. doi: 10.1016/j.porgcoat.2012.08.006

7. A.A. Hermas, S.S. Al-Juaid, S.A. Al-Thabaiti, A.H. Qusti smd M. Abdel Salam, In situ electropolymerization of conducting polypyrrole/carbon nanotubes composites on stainless steel: Role of carbon nanotubes types, Prog. Org. Coat., 2012, 75, 404-410.

8. N. Brown, M.R. Kessler, N.R. Sottos and S.R. White, In situ poly(urea-formaldehyde) microencapsulation of dicyclopentadiene, J. Microencapsulation, 2003, 20, no. 6, 719730.

9. M. Samadzadeh, S.H. Boura, M. Peikari, S.M. Kasiriha and A. Ashrafi, A review on self-healing coatings based on micro/nanocapsules, Prog. Org. Coat., 2010, 68, no. 3, $159-164$.

10. S. Mallakpour and M. Dinari, Fabrication of polyimide/titania nanocomposites containing benzimidazole side groups via sol-gel process, Prog. Org. Coat., 2012, 75, $373-378$. 
11. G. Lagaly, O. Schulz und R. Zimehl, Dispersionen und Emulsionen, eine Einführung in die Kolloidik feinverteilter Stoffe einschließlich der Tonminerale (Dispersions and Emulsions, an Introduction to the Colloid Chemistry of Finely Dispersed Substances Including Clay Minerals), Steinkopff, Darmstadt, 1997, 215 pp. (in German).

12. V.G. Babak, Colloidnaya khimiya v mikrokapsulirovanii (Colloid chemistry in the technology of microcapsules), Sverdlovsk, Publishing house of the Ural University, 1991, 171 pp. (in Russian).

13. D. Brown, Angew. Chem., Int. Ed., 1976, 88, no. 15, 487-495 (in German).

14. L.S. Krokhina, V.N. Kuleznev, L.R. Lyusova and V.A. Glagolev, Vliyanie rastvoritelya na vsaimodejstvie polimerov $\mathrm{v}$ rastvore i svoistva poluchaemykh plenok (Effect of a solvent on the interaction of polymers in a solution and the properties of the resulting films), Vysokomolekulyarnye soedineniya (High Molecular Compounds), 1976, 18A, no. 3, 663-668 (in Russian).

15. H.-D. Dörfler, Grenzflächen und kolloid-disperse Systeme (Interfaces and Colloidal Disperse Systems), Springer-Verlag, Berlin-Heidleberg, 2002, 990 pp. (in German).

16. D.S. Xiao, M.Z. Rong and M.Q. Zhang, A novel method for preparing epoxycontaining microcapsules via UV irradiation-induced interfacial copolymerization in emulsions, Polymer, 2007, 48, 4765-4776.

17. F. Ganachaud and J.L. Katz, Nanoparticles and Nanocapsules Created Using the OuzoEffect, Spontaneous Emulsification as an Alternative to Ultrasonic and High-Shear Devices, Chem. Phys. Chem., 2005, 6, 209-216.

18. D.V. Andreeva and D.G. Schukin, Smart self-repairing protective coatings, Mater. Today, 2008, 11, no. 10, 24-30.

19. C. Gross-Heitfeld, Chemical and Physical Modification of the Capsule Membrane of Polyalkylcyanoacrylate-Based Nanocapsules, Dissertation, 2015, 234 pp. (in German).

20. V.A. Golovin, A.B. Ilyin, V.T. Kuznets and A.R. Vartapetyan, Sposob zashity ot korrosii metallicheskikh poverhnostei ingibirovannymi polimernymi compozitsiyami I microkapsuly s ingibitorom korrosii (Method of protection against corrosion of metal surfaces with inhibited polymer compositions and microcapsules with corrosion inhibitor), Pat. 2358036 Russian Federation, IPC C 23 F 11/00, C 09 D 5/08, publ. 10.06.2009, Byul. no. 16 (in Russian).

21. V.I. Chueshov, E.V. Gladukh and I.V. Saiko, Theory of industrial drugs, Vinnitsa, Nova Kniga, 2014, 696 pp. (in Russian).

22. H.J. Cantowe, Part of the Advances in Polymer Science book series - POLYMER, volume 63, Weinheim, VerlagChemie, 1976, 151 pp. (in German).

23. Y.L. Meltzer, Water-soluble Resins and polymers. Technology and Applications, no. 57 of Series: Chemical Technology reviews, New York, Noyes Data Corp., 1976, 371 pp.

24. T. Nesterova, K. Dam-Johansen, T.L. Pedersen and S. Kiil, "Microcapsule-Based SelfHealing Anticorrosive Coatings: Capsule Size, Coating Formulation, and Exposure Testing., Prog. Org. Coat., 2012, 75, no. 4, 309-318. 
25. Y. Li, G.Z. Liang, J.Q. Xie, J. Gou and L. Li, Thermal Stability of Microencapsulated Epoxy Resin with Poly(Urea-Formaldehyde), Polym. Degrad. Stab., 2006, 91, 23002306.

26. S.D. Bruck6 The Role of Conduction of Macromolecules in Certain Biomedical Problems, Polymer, 1975, 16, 409-417.

27. S. Priyanka, B. Shisode, C. Patil and P.P. Mahulikar, Preparation and Characterization of Microcapsules Containing Soybean Oil and Their Application in Self-Healing Anticorrosive Coatings, Polym.-Plast. Technol. Eng., 2018, 57, no. 13, 1334-1343.

28. R.S. Jadhav, V. Mane, A.V. Bagle, D.G. Hundiwale, P.P. Mahulikar and G. Waghoo, Synthesis of MulticorePhenol Formaldehyde Microcapsules and Their Application in Polyurethane Paint Formulation for Self-Healing Anticorrosive Coating, Int. J. Ind. Chem., 2013, 4, no. 31, 1-9.

29. P.S.D. Tatiya, R.K. Hedaoo, P.P. Mahulikar and V.V. Gite, Novel Polyurea Microcapsules Using Dendritic Functional Monomer Synthesis, Characterization, and Its Use in Self-Healing and Anticorrosive Polyurethane Coatings, Ind. Eng. Chem. Res., 2013, 52, 1562-1570.

30. Abdel Salam Hamdy Makhlouf, Handbook of smart coatings for materials protection, Elsevier, Woodhead Publishing, 2014, 656 pp.

31. S.A.S. Dias, G.A. Nogueira, S.V. Lamaka and T.C. Diamantino, Sol-gel coatings modified with zeolite fillers for active corrosion protection of AA2024, Corros. Sci., 2012, 62, 153-162.

32. A.C. Balaskas, I.A. Kartsonakis and G.C. Kordas, Improvement of anti-corrosive properties of ORMOSIL coatings with loaded inorganic nanocontainers for protection of AA 2024-T3. Self-healing Coatings: Effectiveness and Implementation, Prog. Org. Coat., 2012, 74, no. 3, 418-426.

33. I.A. Kartsonakis, A.C. Balaskas and G.C. Kordas, Influence of cerium molybdate containers on the corrosion performance of epoxy coated aluminum alloys 2024-T3, Corros. Sci., 2011, 53, 3771-3779.

34. Z. Iqbal, T. Rehg, J. Guiheen and D. Narasimhan, Corrosion resistant coated fuel cell plate with graphite protective barrier and method of making the same, US Patent 6,864,007, 2005.

35. P. Yuan, D. Tan, F. Annabi-Bergaya, Properties and applications of halloysite nanotubes: recent research advances and future prospects, Appl. Clay Sci., 2015, 112113, 75-93.

36. Yu. Lvov, W. Wang, L. Zhang and R. Fakhrullin, Halloysite Clay Nanotubes for Loading and Sustained Release of Functional Compounds, Adv. Mater., 2016, 28, no. 6, 1227-1250.

37. Y. Hao, F. Yu, R. Lv, C. Ma, Z. Zhang, Y. Rui, L. Liu, W. Cao and B. Xing, Carbon Nanotubes Filled with Different Ferromagnetic Alloys Affect the Growth and Development of Rice Seedlings by Changing the C:N Ratio and Plant Hormones 
Concentrations, PLoS One, 2016, 11, no. 6, e0157264, published online 2016 Jun 10, doi: 10.1371/journal.pone.0157264, PMCID: PMC4902202.

38. J. Ouyang, D. Mu, Y. Zhang and H. Yang, Mineralogy and Physico-Chemical Data of Two Newly Discovered Halloysite in China and Their Contrasts with Some Typical Minerals, Minerals, 2018, 8, no. 3, 108.

39. E. Abdullayev and Y. Lvov, Clay nanotubes for corrosion inhibitor encapsulation release control with end stoppers, J. Mater. Chem., 2010, 20, no. 32, 6681-6687.

40. C. Preetz, A. Hauser, G. Hause, A. Kramer and K. Mäder, Application of atomic force microscopy and ultrasonic resonator technology on nanoscale: distinction of nanoemulsions from nanocapsules, Eur. J. Pharm. Sci., 2010, 39, no. 1-3, 141-151.

41. G.R. Nixon, S.A.H. Khalil and J.E. Carles, Complex Coacervation: Microcapsule Formation, J. Pharm. Pharmacol., 1968, 20, 528-538.

42. R.E. Phares and G.J. Sperandio, Coating pharmaceuticals by coacervation, J. Pharm. Sci., 1964, 53, 515-521.

43. N. Altinbas, C. Fehmer, A. Terheiden, A. Shukla, H. Rehage and C. Mayer, Alkylcyanoacrylate nanocapsules prepared from mini-emulsions: A comparison with the conventional approach, J. Microencapsulation, 2006, 23, no. 5, 567-581.

44. F. Ulmann, W. Foerst and H. Buchholz-Meisenheimer, Ullmann's Encyclopedia of Industrial Chemistry, 4th Edition, VerlagChemie, Weinheim, 1972, pp. 188-198.

45. M. Gallardo, G. Couarraze, B. Denziot, I. Treupel, P. Couvreur and F. Puisieux, Study of the mechanisms of formation of nanoparticles and nanocapsules of polyisobutyl-2cyanoacrylate, Int. J. Pharm., 1993, 100, no. 1-3, 55-64.

46. N. Al Khouri Fallouh, L. Roblot-Treupel, H. Fessi, J. Devissaguet and F. Puisieux, Development of a new process for the manufacture of polyisobutylcyanoacrylate nanocapsules, Int. J. Pharm., 1986, 28, no. 2-3, 125-132.

47. S. Radlewitz, Mikrokapseln als polymere Bindersysteme für die Vormgebung von keramischen Werkstoffen über Schlickerguss (Microcapsules as polymeric binder systems for the premise of ceramic materials via slip casting), Muenchen, Herbert Utz Verlag, 1999, 164 pp. (in German).

48. A.E. Chalykh, Diffuziya v polimernykh sistemakh (Diffusion in polymer systems), Moscow, Khimiya, 1987, 312 pp. (in Russian).

49. S.A. Reitlinger, Pronitsaemost polimernykh materialov (Permeability of polymeric materials), Moscow, Khimiya, 1974, 272 pp. (in Russian).

50. T.G. Fox and P.J. Flory, The glass temperature and related properties of polystyrene. Influence of molecular weight, J. Polymer Sci., 1954, 14, no. 76, 321-325.

51. F.M. Uhl, S.P. Davuluri, S.-C. Wong and D.C. Webster, Polymer Films Possessing Nanoreinforcements via Organically Modified Layered Silicate, Chem. Mater., 2004, 16, no. 6, 1135-1142.

52. A.Yu. Mulin and A.D. Yakovlev, Vliyaniye termookislitel'noi destruktsii na deformatsionnye svoystva polipropilenovykh plenok (The effect of thermal-oxidative 
degradation on the structure and deformation properties of polypropylene films), Vysokomolekulyarnye soedineniya (High molecular weight compounds), B11, 1969, 261-264 (in Russian).

53. V.D. Solodovnic, Mikrokapsulirovanie (Microencapsulation), Moscow, Khimiya, 1980, 216 pp. (in Russian).

54. F.J. Maile, T. Schauer and C.D. Eisebbach, Evaluation of corrosion and protection of coated metals with local ion concentration technique (LICT), Progr. Org. Coat., 2000, 38, no. 2, 111-116.

55. L.M. Calle, W. Li, J.W. Buhrow and S.T. Jolley, Selbsstaendiger korrosionsschutz. Multifunktionelle beschichtungen reagieren automatisch und rasch auf Korrosion (Multifunctional coatings react automatically and quickly to corrosion), Farbe und Lack (Paint and Varnish), 2012, 4, 25-29 (in German).

56. V.A. Golovin, S.A. Dobriyan and V.B. Lukin, The growth of the insulating ability of polymer coatings with active solid-phase and inhibiting additives upon exposure to aggressive media, Korroz.: mater., zashch., 2018, no. 6, 23-31 (in Russian).

57. V.A. Golovin and S.A. Dobriyan, EIS study of inhibited polymeric Zn-filled primers in a model of sea water, Korroz.: mater., zashch., 2016, no. 6, 42-47 (in Russian).

58. Yu.I. Kuznetsov, Physico-chemical aspects of the inhibition of corrosion of metals in aqueous solutions, Russ. Chem. Rev., 2004, 73, no. 1, 75-87.

59. X. Shi, T.A. Nguyen, Z. Suo, Y. Liu and R. Avci, Effect of nanoparticles on the anticorrosion and mechanical properties of epoxy coating, Surf. Coat. Technol., 2009, 204, no. 3, 237-245.

60. M.R. Bagherzadeh and F. Mahdavi, Preparation of Epoxy/Clay Nanocomposite and Investigation on its Anti-Corrosive Behavior in Epoxy Coating, Progr. Org. Coat., 2007, 60, 117-120.

61. V.A. Golovin, A.B. Ilyin and A.D. Aliyev, Mass transfer of phosphorus-containing corrosion inhibitors in epoxy protective coatings, Korroz.: mater., zashch., 2018, no. 8, 18-24 (in Russian).

62. D.Y. Wu, S. Meure and D. Solomon, Self-Healing Polymeric Materials: A Review of Recent Developments, Prog. Polym. Sci., 2008, 33, 479-522.

63. M. Wanner, K. Krawczyk, T. Schauer, E. Lachery, S. Peeterbroeck, M. Poelman, V. Stenzel, M. Cybik and C. Mayer. Evaluation of the "self-healing", corrosion inhibitive effect of nanocontainers, micro- and nanocapsules in anticorrosive paints, Coatings Science International - COSI, 2015, 36-40.

64. S.K. Grosh, Self-Healing Materials: Fundamentals, design Strategies and Applications, Willey-VCH Verlag GmbH\& Co. KGaA, Weinheim, 2009, ISBN: 978-3-527-31829-2, $306 \mathrm{pp}$.

65. A. Tiwari, L.H. Hihara and J. Rawlins, Intelligent coatings for corrosion control, Butterworth Heinemann is an imprint of Elsevier. First edition, 2015, p. 746. 
66. M. Cybik, Funktionalisierung von Oberflächendurch Integration von polyalkylcyanoacrylat-Nanokapseln (Functionalization of Surfaces by Integration of Polyalkylcyanoacrylate Nanocapsules), Dissertation, Duisburg-Essen, 2016, 159 pp. (in German).

67. M. Binnewies, M. Jackel, H. Willner and G. Rayner-Canham, General and Inorganic Chemistry, 1st ed., Spektrum Akademischer Verlag, 2004, 818 pp.

68. P. Sorlier, D. Denuziere, C. Viton and A. Domard, Relation between the Degree of Acetylation and the Electrostatic Properties of Chitin and Chitosan, Biomacromolecules, 2001, 2, no. 3, 765-772.

69. G.F. Payne and R. Raghavans, Chitosan: a soft interconnect for hierarchical assembly of nano-scale components, Soft Matter, 2007, 3, no. 5, 521-527.

70. J.H. Pa and T.L. Yu, Light scattering study of chitosan in acetic acid aqueous solutions, Macromol. Chem. Phys., 2001, 202, no. 7, 985-991.

71. O.V. Dement'eva, A.M. Semiletov, A.A. Chirkunov, V.M. Rudoy and Yu.I. Kuznetsov, Sol-Gel Synthesis of $\mathrm{SiO}_{2}$ Containers Using Micelles of an Anionic Corrosion Inhibitor as a Template and the Prospects of Creation Protective Coatings Based on Them, Colloid J., 2018, 80, no. 5, 474-483.

72. L.P. Kazansky, Y.I. Kuznetsov, N.P. Andreeva and Y.G. Bober, Self-assembled monolayers of flufenaminate anions on mild steel surface formed in aqueous solution, Appl. Surf. Sci., 2010, 257, no. 4, 1166-1174.

73. M.O. Agafonkina, Yu.I. Kuznetsov and N.P. Andreeva, Inhibiting properties of carboxylates and their adsorption on copper from aqueous solutions, Zh. Phis. Khim. (Russ. J. Phys. Chem.), 2015, 89, no. 6, 1013-1019 (in Russian).

74. A.M. Semiletov, Yu.I. Kuznetsov and A.A. Chirkunov, Protection of D16 alloy against atmospheric corrosion by thin layers formed in aqueous solutions of salts of organic acids and trialkoxysilanes, Korroz.: mater., zashch., 2017, no. 10, 16-22 (in Russian).

75. C. Schatz, C. Pichot, T. Delair, C. Viton and A. Domard, Static light scattering studies on chitosan solution: from macromolecular chains to colloidal dispersions, Langmuir, 2003, 19, no. 23, 9896-9903. doi: 10.1021/1a034410n

76. M. Soltau, Entwicklung polymerer Inhibitorkonzepte (Development of polymeric inhibitor concepts), Farbe und Lack (Paint and varnish), 2012, no. 6, pp. 20-24 (in German).

77. Straetmans High TAC GmbH, Highlight Product - Additive G50. http://www.hightac.de/, $7 \mathrm{~S}$.

78. Evonik Industries, Safety Data Sheet according to EC Regulation 1907-2006, Rewocoros AC 28, 7 p.

79. Evonik Industries, Safety Data Sheet according to EC Regulation 1907-2006, Rewocoros AC 101, 8 p. 
80. S. Beuermann, Einbindung von Polyalkylcyanoacrylat-Nanokapseln in Metalloberflächen (Integration of PolyalkylcyanoacrylateNanocapsules in Metal surfaces), Dissertation, Duisburg-Essen, 2015, 176 pp. (in German).

81. V.A. Golovin, A.B. Ilyin, A.D. Aliev, V.A. Shchelkov and V.A. Rabinkov, A study on the desorption of phosphonic acids, corrosion inhibitor precursors, from polymer microcapsules, Int. J. Corros. Scale Inhib., 2018, 7, no. 2, 165-174. doi: 10.17675/2305-6894-2018-7-2-4

82. T. Nesterova, D. Johansenk and S. Kiil, Synthesis of durable microcapsules for selfhealing anticorrosive coatings, Self-healing Coatings: Effectiveness and Implementation. Book of abstracts, 2012, p. 22.

83. D.Y. Wu, S. Meure and D. Solomon, Self-healing polymeric materials: A review of recent developments, Prog. Polym. Sci., 2008, 33, 479-522.

84. E.B. Murphy and F. Wudl. The world of smart healable materials, Prog. Polym. Sci., $2010,35,223-251$.

85. S. Burattini, B.W. Greenland, D. Chappell, H.M. Colquhoun and W. Hayes, Healable polymeric materials: a tutorial review, Chem. Soc, Rev., 2010, 39, no. 6, 1973-1985. 